\title{
Effects of Basalt Fibres on Mechanical Properties of Concrete
}

\author{
A. M. El-Gelani ${ }^{1}$, C.M. $\mathrm{High}^{2}$, S. H. Rizkalla ${ }^{3}$ and E. A. Abdalla ${ }^{4}$ \\ ${ }^{1,4}$ University of Tripoli, Civil Engineering Department, Tripoli, Libya \\ ${ }^{2}$ Stweart Engineering, Charlotte N.C., USA \\ ${ }^{3}$ N.C. State University, Civil, Construction and Environmental Engineering Department, Raleigh N.C., USA
}

\begin{abstract}
This paper presents the results of an experimental program carried out to investigate the effects of Basalt Fibre Reinforced Polymers (BFRP) on some fundamental mechanical properties of concrete. Basalt fibres are formed by heating crushed basalt rocks and funnelling the molten basalt through a spinneret to form basalt filaments. This type of fibres have not been widely used till recently. Two commercially available chopped basalt fibres products with different aspect ratios were investigated, which are dry basalt (GeoTech Fibre) and basalt pre-soaked in an epoxy resin (GeoTech Matrix) .The experimental work included compression tests on 96 cylinders made of multiple batches of concrete with varying amounts of basalt fibre additives of the two mentioned types, along with control batches containing no fibres. Furthermore, flexural tests on 24 prisms were carries out to measure the modulus of rupture, in addition to 30 prisms for average residual strength test. Results of the research indicated that use of basalt fibres has insignificant effects on compressive strength of plain concrete, where the increase in strength did not exceed about $5 \%$. On the other hand, results suggest that the use of basalt fibres may increase the compressive strength of concrete containing fly as up top $40 \%$. The rupture strength was increased also by $8 \%$ to $28 \%$ depending on mix and fibre types and contents. Finally, there was no clear correlation between the average residual strength and ratios of basalt fibres mixed with the different concrete batches.
\end{abstract}

\section{Introduction}

Fibre-reinforced concrete (FRC) has been produced using steel, carbon and glass fibres for several years. These existing forms of FRC have proven that the addition of fibres can enhance the mechanical characteristics of concrete. However, basalt fibre-reinforced concrete (BFRC) may also have the potential to improve the mechanical properties of concrete by increasing mainly the concrete's tensile strength, fracture toughness and controlling cracking.

The research program included an investigation of the fundamental properties of BFRC produced using two types of chopped basalt fibre products as additives. This investigation of BFRC was a preliminary study which provided an evaluation of the chopped basalt fibres $s$ an additive to enhance the characteristics of concrete.

Basalt fibres are a material made from extremely fine fibres of basalt. It is similar to carbon fibre and fibreglass, having better physico-mechanical properties than fibreglass, but being significantly cheaper than carbon fibre. Basalt fibres are made from a single material, crushed basalt rock, from a carefully chosen quarry source, and unlike other materials such as fibreglass, essentially no materials are added. The basalt is simply washed and then melted. The manufacture of basalt fibres require the melting of the quarried basalt rock at about $1400^{\circ} \mathrm{C}$. The molten basalt rock is then extruded through small nozzles (spinnerets) to produce continuous filaments of basalt fibres. Figure 1 illustrates the stages of producing continuous basalt fibers. There are three main manufacturing techniques, which are centrifugal-blowing, centrifugal-multiroll and die-blowing [1].

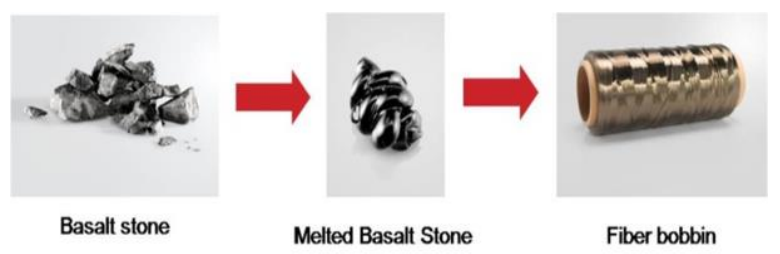

Fig. 1. Manufacturing of basalt fibres.

Basalt fibres are used in several applications, other than as concrete additives, such as military and aerospace applications, in addition to automotive industries and windmill blades. Basalt fibres exhibit considerable tensile strength in the longitudinal direction [2]. Its mechanical properties suggest that adding this type of fibres to concrete may enhance the rupture strength of concrete. However, only a few studies have investigated the mechanical properties of BFRC. This paper aims to 
determine the potential effectiveness of using basalt fibres as additives to concrete. Borhan studied the compressive and splitting tensile strengths of BFRC with small fibre volume fractions ranging from $0.1 \%$ to $0.5 \%$ [3]. Test results indicated that increasing the basalt fibre content increased the splitting tensile strength of the concrete without significantly affecting the concrete's compressive strength. That study reports also a decrease in concrete slump as the basalt fibre volume content was increased.

Also, Yang and Lian tested 480 specimens to determine the mechanical properties of BFRC, and to investigate the optimum range of basalt fibre content. This research concluded that adding basalt fibres to concrete can increase the compressive, splitting tensile and flexural strengths of plain concrete. Furthermore, this research suggested that concrete with a basalt fibre volume content between $0.3 \%$ and $0.5 \%$ resulted in the highest measured strength increases [4].

Another experimental program investigated the mechanical properties of concrete with the addition of basalt fibres that were pre-soaked in epoxy [5]. Three different pre-soaked basalt fibre lengths $(10 \mathrm{~mm}, 20 \mathrm{~mm}$ and $30 \mathrm{~mm})$ and three different fibre dosages $\left(3 \mathrm{~kg} / \mathrm{m}^{3}, 5\right.$ $\mathrm{kg} / \mathrm{m}^{3}$ and $7 \mathrm{~kg} / \mathrm{m}^{3}$ ) were examined in this study. The results showed that as the basalt fibre dosage and fibre length increased, the measured slump decreased. Moreover, according to this study, the presence of the pre-soaked basalt fibres did not significantly affect the compressive strength. The results indicated that the epoxy-presoaked fibres increased the flexural strength of each concrete batch. The splitting tensile strength was increased for each batch with $30 \mathrm{~mm}$ long basalt fibres. This study concluded that adding $30 \mathrm{~mm}$ basalt fibres at a dosage range of $3 \mathrm{~kg} / \mathrm{m}^{3}$ to $5 \mathrm{~kg} / \mathrm{m}^{3}$ resulted in improved mechanical properties and acceptable workability.

\section{Experimental program}

The main objective of this paper is to determine the fundamental mechanical properties of BFRC. These include compressive, flexural and average residual strengths. The experimental program included two different concrete mixes, and the basalt fibre type and matrix ratios were varied for each mix. The effect of the basalt fibres was determined by comparing test results to control concrete specimens without fibres.

\subsection{Concrete materials and mix design}

Test specimens were cast using two different concrete mix designs. Mix design " $\mathrm{A}$ " was a standard concrete mix with a target compressive strength of $21 \mathrm{MPa}$. Mix design " $\mathrm{B}$ " contained additional fly ash and admixtures. Table 1 describes the ingredients of each concrete mix design and the weight of each ingredient per cubic meter of concrete.

The SSD specific gravity and percent moisture absorption of the coarse and fine aggregates were determined in accordance with ASTM C127 and C128 respectively [6,7]. The results of the tests are shown in Table 2.

Table 1. Concrete mix designs " $A$ " and "B".

\begin{tabular}{|c|c|c|}
\hline \multirow{2}{*}{ Material } & \multicolumn{2}{|c|}{ Weight $\left(\mathbf{K g} / \mathbf{m}^{\mathbf{3}}\right)$} \\
\cline { 2 - 3 } & Mix A & Mix B \\
\hline Cement & 307 & 217 \\
\hline Fly ash & 0 & 145 \\
\hline Water & 171 & 143 \\
\hline Fine aggregate & 749 & 698 \\
\hline Coarse aggregate & 988 & 1016 \\
\hline Air entrainer & $0.13 \mathrm{lt}$ & $0.17 \mathrm{lt}$ \\
\hline Superplasticizer & 0 & $0.63 \mathrm{lt}$ \\
\hline Accelerator & 0 & $0.71 \mathrm{lt}$ \\
\hline
\end{tabular}

Table 2. Aggregate characterization results.

\begin{tabular}{|c|c|c|}
\hline Material & $\begin{array}{c}\text { SSD specific } \\
\text { gravity }\end{array}$ & $\begin{array}{c}\text { SSD absorption } \\
\mathbf{( \% )}\end{array}$ \\
\hline Fine aggregate & 2.61 & 0.8 \\
\hline Coarse aggregate & 2.62 & 1.0 \\
\hline
\end{tabular}

Two different basalt fibre products were used as additives to the concrete. The two products are known commercially as GeoTech Fibre and GeoTech Matrix, as shown in Figures 2 and 3, respectively. GeoTech fibre is produced using dry basalt fibres, while GeoTech matrix is produced using basalt fibres pre-soaked in an epoxy resin. The aspect ratio (length of fibre divided by fiber diameter) of the GeoTech fibre is significantly greater than that of the GeoTech matrix.

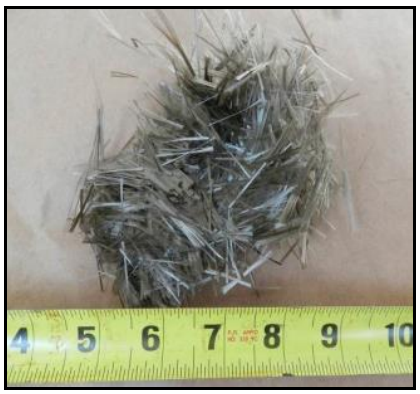

Fig. 1. GeoTech fibre.

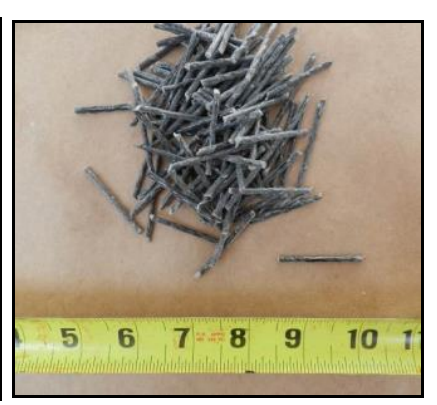

Fig. 2. GeoTech matrix.
For each concrete mix, sub-mixes were generated by varying the basalt content resulting in a total of eight distinct concrete mixes. Table 3 provides an overview of the eight concrete batches and the weight of fibre per cubic meter of concrete for each sub-mix.

Cylinder moulds $(100 \times 200 \mathrm{~mm})$ and prism moulds $(150 \times 150 \times 510 \mathrm{~mm})$ were used for preparing the concrete specimens for compressive and flexural strength tests respectively. In addition, for average residual strength (ARS) test, prism specimens were cut from the flexure test specimens using an abrasive concrete saw. 
Figure 4 shows a finished $100 \times 100 \times 356 \mathrm{~mm} \mathrm{ARS}$ specimen.

Table 3. Fibre contents in concrete batches.

\begin{tabular}{|c|c|c|c|}
\hline \multirow{2}{*}{$\begin{array}{c}\text { Batch } \\
\text { designation }\end{array}$} & \multirow{2}{*}{$\begin{array}{c}\text { Concrete } \\
\text { mix }\end{array}$} & \multicolumn{2}{|c|}{ Basalt fiber $\left(\mathrm{Kg} / \mathrm{m}^{3}\right)$} \\
\hline & & $\begin{array}{l}\text { GeoTech } \\
\text { Fibre }\end{array}$ & $\begin{array}{c}\text { GeoTech } \\
\text { matrix }\end{array}$ \\
\hline $\mathbf{1 A}$ & A (Control) & None & None \\
\hline $2 \mathrm{~A}$ & A & 1.2 & 0.6 \\
\hline$\overline{3 \mathrm{~A}}$ & A & 1.8 & 0 \\
\hline $4 \mathrm{~A}$ & A & 1.2 & 1.2 \\
\hline $1 \mathrm{~B}$ & B (Control) & None & None \\
\hline $2 \mathrm{~B}$ & B & 1.2 & 0.6 \\
\hline $3 \mathrm{~B}$ & B & 1.8 & 0 \\
\hline $4 \mathrm{~B}$ & B & 1.2 & 1.2 \\
\hline
\end{tabular}

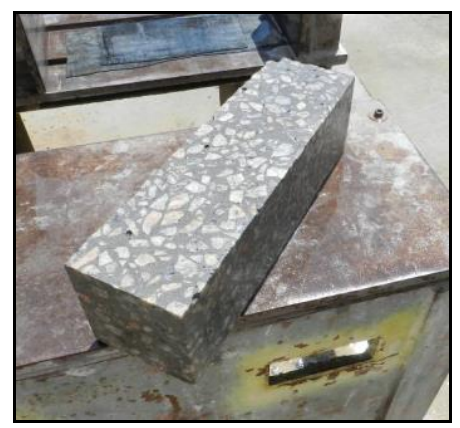

Fig. 4. ARS specimen after cutting.

\subsection{Test setups and testing procedures}

The compressive strength of each sub-mix was measured by testing $100 \times 200 \mathrm{~mm}$ cylinders at 3,7 and 28 days in accordance with ASTM C39 [8]. The test specimens were loaded at a constant rate of approximately $0.24 \mathrm{MPa} / \mathrm{s}$. The flexural strength of each sub-mix was determined for $150 \times 150 \times 510 \mathrm{~mm}$ prisms in accordance with ASTM C78 [9]. Flexural specimens were tested using an apparatus suitable for third-point loading, Figure 5. Flexural specimens were turned on their side from the position as cast and loaded at a constant rate of $8 \mathrm{KN} / \mathrm{min}$ until failure. Modulus of rupture, $\mathrm{R}$, of each flexural specimen was also calculated.

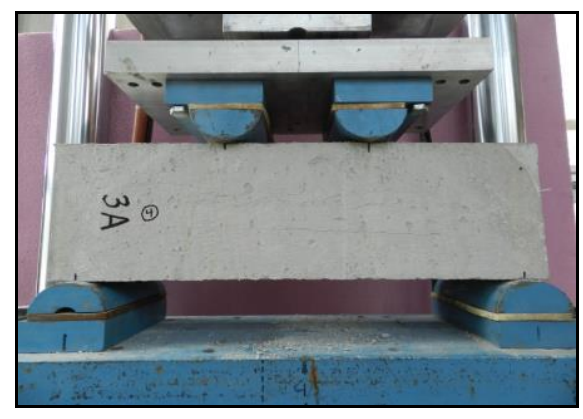

Fig. 5. BFRC flexural specimen in the loading apparatus.
The average residual strength (ARS) was determined in accordance with ASTM C1399 [10]. ARS specimens, supported by a steel plate, were turned on their sides from the position as cast and initially loaded at a constant displacement rate of $0.635 \mathrm{~mm} / \mathrm{min}$. The purpose of the steel plate was to control the deflection of the beam once a flexural crack was formed.

The initial loading was terminated once the specimen experienced a mid-span displacement of $0.2 \mathrm{~mm}$ relative to the outside supports. Mid-span displacement was taken as the average of two transducer readings positioned on either sides of the test specimen at mid-span. The two transducers were supported by a rigid yoke which rested on top of the specimen directly above the outside supports. Figure 6 shows an ARS specimen positioned in the testing apparatus before the application of the initial loading phase.

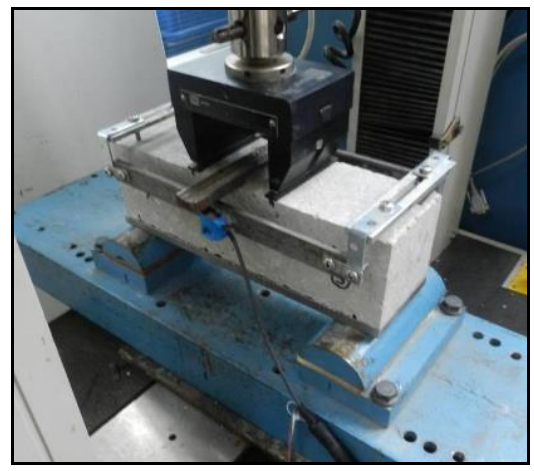

Fig. 6. ARS setup for the initial loading phase.

After the initial loading phase, the specimen was unloaded, the steel plate was removed, and the transducers were re-zeroed. The specimen was then reloaded at a displacement rate of $0.635 \mathrm{~mm} / \mathrm{min}$ until the specimen experienced a mid-span displacement of 1.27 $\mathrm{mm}$. During the initial and reloading phases, applied load and mid-span displacement data were continuously recorded. The ARS was recorded based on the loaddeflection data and the dimensions of each specimen.

\section{Test results and analysis}

\subsection{Compressive strength}

Figures 7 and 8 show typical failures of tested compressive specimens, while the average measured test results at 3, 7 and 28 days for the mixes $\mathrm{A}$ and $\mathrm{B}$ are given in Table 4. Only the amount of fibres was intentionally altered among concrete batches of the same mix, however, other parameters influencing the compressive strength of the concrete inevitably varied slightly from one batch to another. Figures 9 and 10 show the average measured 28 days strength of mixes A and B respectively.

An initial assessment of the results indicates the use of GeoTech matrix and GeoTech fibres did not affect the compressive strength of the concrete of mix A. However, test results show some noticeable increase in the 
compressive strength for concrete sub-mixes of mix B containing GeoTech matrix and Geo-Tech fibres. Table 5 shows the percentage of increase or decrease in the 28 days compressive strength of each sub-mix with respect to the associative control mix.
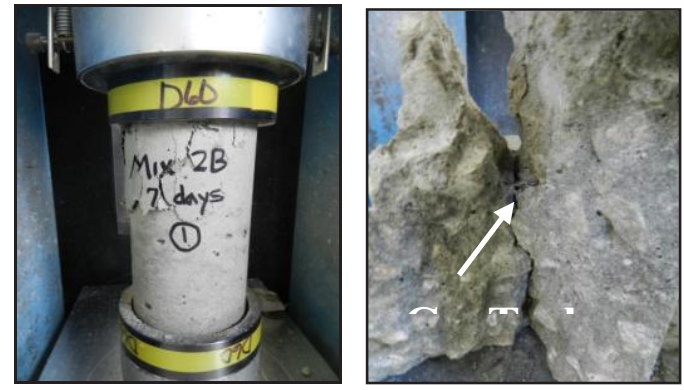

Fig. 7. Typical failure. Fig. 8. Exposed GeoTech matrix after failure.

Table 4. Compressive test results.

\begin{tabular}{|c|c|c|c|}
\hline \multirow{2}{*}{$\begin{array}{c}\text { Batch } \\
\text { designation }\end{array}$} & \multicolumn{3}{|c|}{ Compressive strength (MPa) } \\
\cline { 2 - 4 } & 3 days & 7 days & 28 days \\
\hline 1A & 14.6 & 16.9 & 23.1 \\
\hline 2A & 14.6 & 18.9 & 23.2 \\
\hline 3A & 15.3 & 19.3 & 24.4 \\
\hline 4A & 10.6 & 14.1 & 18.4 \\
\hline 1B & 11.2 & 14.1 & 21.1 \\
\hline 2B & 14.7 & 18.3 & 25.3 \\
\hline 3B & 14.3 & 18.0 & 24.3 \\
\hline 4B & 18.5 & 22.7 & 29.6 \\
\hline
\end{tabular}

Table 5. Percentage increase or decrease in 28 day compressive strength.

\begin{tabular}{|c|c|c|c|c|}
\hline \multirow{4}{*}{$f_{c}^{\prime}$} & \multicolumn{4}{|c|}{ Mix } \\
\cline { 2 - 5 } & $\mathbf{1 A}$ & $2 \mathrm{~A}$ & $3 \mathrm{~A}$ & $4 \mathrm{~A}$ \\
\cline { 2 - 5 } $\mathbf{M P a}$ & 23.1 & $\begin{array}{c}23.3 \\
(1.2 \% \uparrow)\end{array}$ & $\begin{array}{c}24.4 \\
(5.7 \% \uparrow)\end{array}$ & $\begin{array}{c}18.4 \\
(20.3 \% \downarrow)\end{array}$ \\
\cline { 2 - 5 } $\mathbf{( \%} \uparrow \downarrow)$ & $\mathbf{1 B}$ & $2 \mathrm{~B}$ & $3 \mathrm{~B}$ & $4 \mathrm{~B}$ \\
\cline { 2 - 5 } & 21.1 & $\begin{array}{c}25.3 \\
(19.9 \% \uparrow)\end{array}$ & $\begin{array}{c}24.3 \\
(15.3 \% \uparrow)\end{array}$ & $\begin{array}{c}29.6 \\
(40.5 \% \uparrow)\end{array}$ \\
\hline
\end{tabular}

The measured compressive strengths at 3 and 7 days were calculated as a fraction of the measured compressive strength at 28 days to determine the effect of the basalt fibre products on the compressive strength at early age, if any.

The analysis indicates that the presence of the basalt additives had little effect on the percentage of compressive strength gained at 7 days for mix A. It can be seen also that the 3 and 7 days fraction of 28 days compressive strength of mix B sub-mixes containing basalt additives are clearly higher than the control batch. Mix 4B gained $10 \%$ more of its 28 days compressive strength at 3 days and 7 days than the control mix. Therefore, the test results suggest that there is some possibility for a correlation between the fibre volume fraction and the development of early strength for mix B. This correlation may be related, as well, to the presence of fly ash in this mix.
Table 6. Early ages compressive strengths as fractions of 28 days strength.

\begin{tabular}{|c|c|c|}
\hline $\mathbf{M i x}$ & $f_{c}^{\prime} \mathbf{3 d} / f_{c}^{\prime} \mathbf{2 8 d}$ & $f_{c}^{\prime} \mathbf{7 d} / f_{c}^{\prime} \mathbf{2 8 d}$ \\
\hline $\mathbf{1 A}$ & 0.63 & 0.73 \\
\hline 2A & 0.63 & 0.81 \\
\hline 3A & 0.63 & 0.79 \\
\hline 4A & 0.58 & 0.77 \\
\hline 1B & 0.53 & 0.67 \\
\hline 2B & 0.58 & 0.72 \\
\hline 3B & 0.59 & 0.74 \\
\hline 4B & 0.63 & 0.77 \\
\hline
\end{tabular}

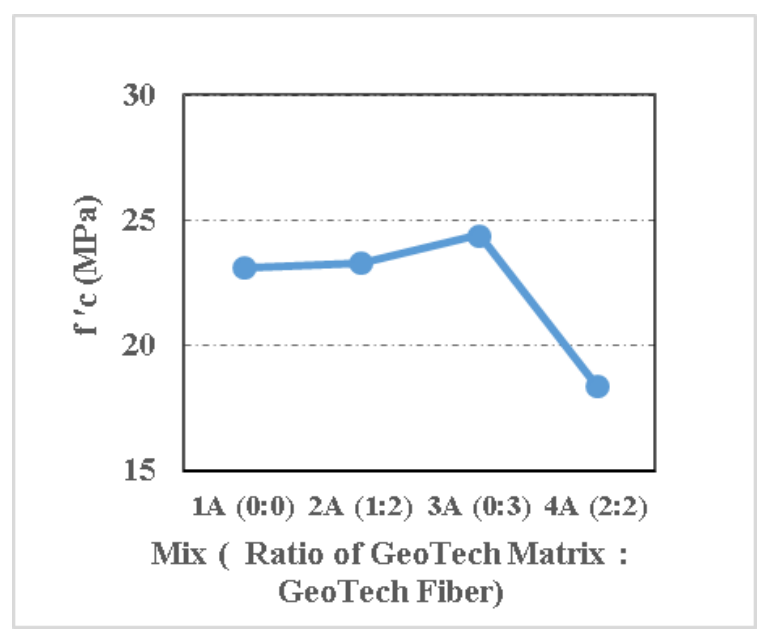

Fig.9. Compressive strength results at 28 days, mix A.

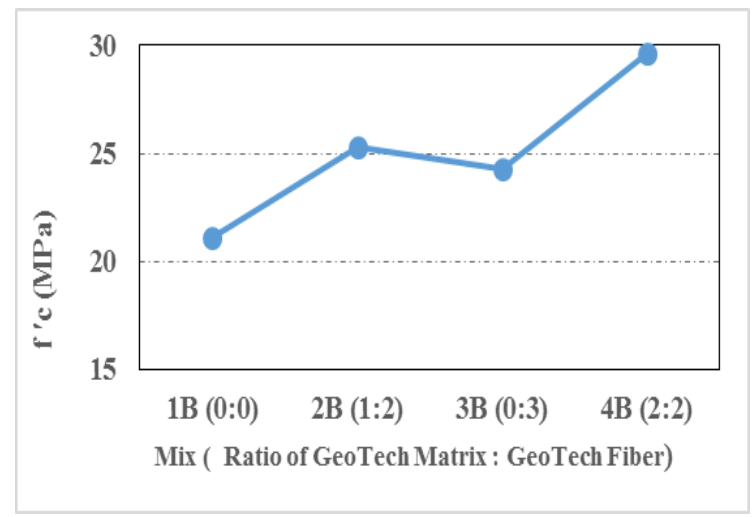

Fig.10. Compressive strength results at 28 days, mix B.

\subsection{Flexural strength}

Figure 11 shows a typical failure of a flexural specimen, and based on the measurements of three prisms for each batch, Table 7 presents the flexural strength for concrete batches of mixes $\mathrm{A}$ and $\mathrm{B}$. 


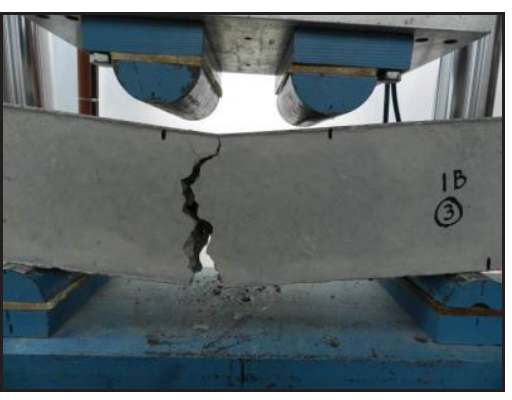

Fig. 11. Typical failure of flexure specimen.

Table 7. Flexural test results.

\begin{tabular}{|c|c|}
\hline $\begin{array}{c}\text { Batch } \\
\text { designation }\end{array}$ & $\begin{array}{c}\text { Flexural } \\
\text { strength (MPa) }\end{array}$ \\
\hline 1A & 3.39 \\
\hline 2A & 3.59 \\
\hline $3 \mathrm{~A}$ & 3.95 \\
\hline 4A & 3.47 \\
\hline 1B & 2.98 \\
\hline 2B & 3.91 \\
\hline 3B & 3.53 \\
\hline 4B & 3.97 \\
\hline
\end{tabular}

The measured test results of the flexural strength were normalized by the square root of the compressive strength at 28 days for each concrete batch. ACI 318-11 equation (9-10) relates the rupture strength $\left(f_{r}\right)$ and compressive strength $\left(f^{\prime} c\right)$ of normal weight concrete as follows [11]:

$f_{r}=0.62\left(f^{\prime} c\right)^{1 / 2}$

The empirically derived coefficient of 0.62 in the ACI equation providers a lower bound value for comparison with results from this study. However, by comparing the normalized rupture strength values of submixes containing fibres to sub-mixes without fibres, the effects of the basalt additives can be accurately observed. Figures 12 and 13 show the normalized average flexural strength values for sub-mixes A and B, respectively.

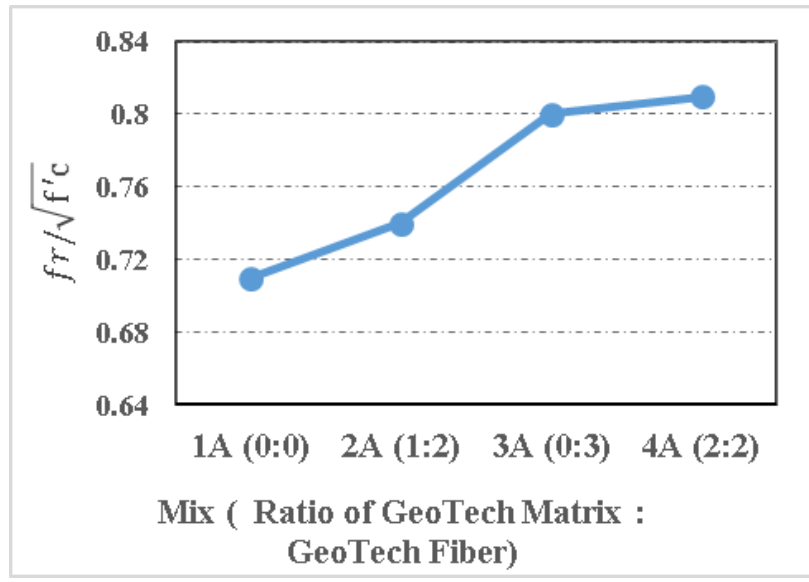

Fig.12. Normalized rupture strength results, mix A.

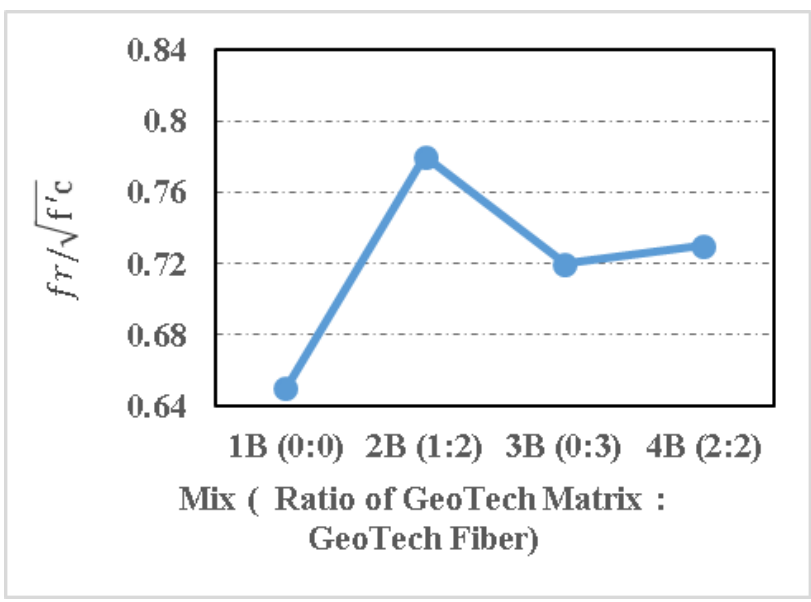

Fig.13. Normalized rupture strength results, mix B.

The normalized rupture strength plots indicate that the addition of basalt fibres increased the rupture strength of mixes A and B. Table 8 shows the percent increase in average rupture strength of each sub-mix with respect to the associative control mix. Test results indicate that the use of both types of basalt fibres provides valuable enhancement to the flexural strength of the concrete which delays the formation of cracks in concrete members.

Table 8. Percentage increase in average rupture strength.

\begin{tabular}{|c|c|c|c|c|}
\hline \multirow{4}{*}{$\frac{f_{r}}{\sqrt{f_{c}^{\prime}}}(\% \uparrow)$} & \multicolumn{4}{|c|}{ Mix } \\
\cline { 2 - 5 } & $\mathbf{1 A}$ & $\mathbf{2 A}$ & $\mathbf{3 A}$ & $\mathbf{4 A}$ \\
\cline { 2 - 5 } & 0.71 & $\begin{array}{c}0.74 \\
(4.2 \% \uparrow)\end{array}$ & $\begin{array}{c}0.80 \\
(12.7 \% \uparrow)\end{array}$ & $\begin{array}{c}0.81 \\
(14.1 \% \uparrow)\end{array}$ \\
\cline { 2 - 5 } & $\mathbf{1 B}$ & $\mathbf{2 B}$ & $\mathbf{3 B}$ & $\mathbf{4 B}$ \\
\cline { 2 - 5 } & 0.65 & $\begin{array}{c}0.78 \\
(20.0 \% \uparrow)\end{array}$ & $\begin{array}{c}0.72 \\
(10.8 \% \uparrow)\end{array}$ & $\begin{array}{c}0.73 \\
(12.3 \% \uparrow)\end{array}$ \\
\hline
\end{tabular}

\subsection{Average residual strength (ARS)}

This test method covers the determination of residual strength of a fibre-reinforced concrete test beam. Figure 14 shows a typical specimen after the application of the initial loading phase and before the application of the reloading phase, while Figure 15 shows the same specimen after the reloading phase. The average residual strength tests results are given in Table 9.

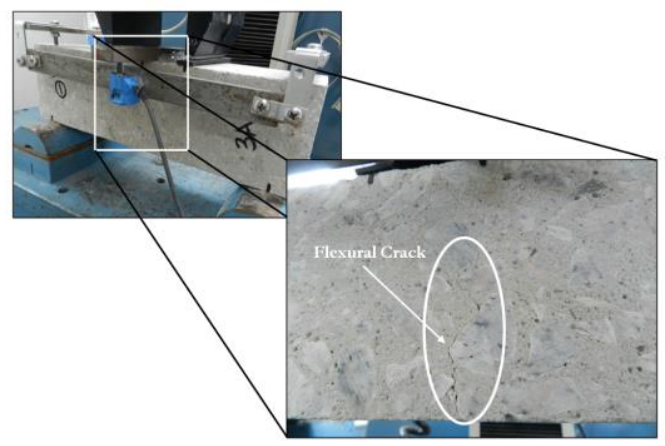

Fig. 14. Typical flexural crack following the ARS initial loading phase. 


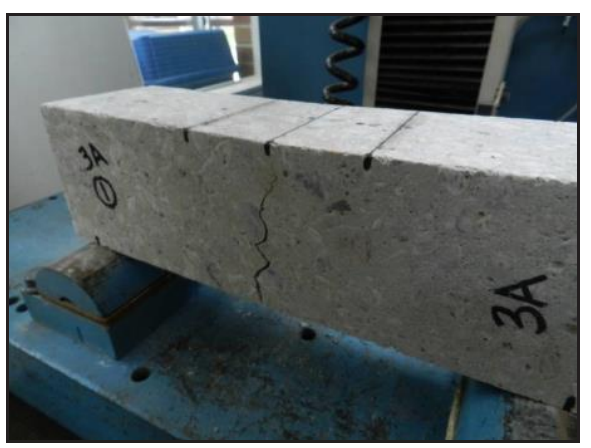

Fig. 15. Crack propagation and widening after the ARS reloading phase.

Table 9. Average residual strength test results.

\begin{tabular}{|c|c|}
\hline $\begin{array}{c}\text { Batch } \\
\text { designation }\end{array}$ & $\begin{array}{c}\text { Average } \\
\text { residual } \\
\text { strength (MPa) }\end{array}$ \\
\hline 1A & - \\
\hline 2A & 0.17 \\
\hline 3A & 0.19 \\
\hline 4A & 0.19 \\
\hline 1B & - \\
\hline 2B & 0.25 \\
\hline 3B & 0.15 \\
\hline 4B & 0.12 \\
\hline
\end{tabular}

The average residual strength of each specimen was calculated using the following equation given by ASTM C1399-10 [10]:

$\mathrm{ARS}=((\mathrm{PA}+\mathrm{PB}+\mathrm{PC}+\mathrm{PD}) / 4) \times \mathrm{k}$

where:

ARS $=$ average residual strength, $\mathrm{MPa}$

$\mathrm{k}=\mathrm{L} / \mathrm{bd}^{2}, \mathrm{~mm}^{2}$

$\mathrm{PA}+\mathrm{PB}+\mathrm{PC}+\mathrm{PD}=$ sum of recorded loads at specified deflections $(0.50,0.75,1.00$ and $1.25 \mathrm{~mm}$, respectively), $\mathrm{N}$

$\mathrm{L}=$ span length, $\mathrm{mm}$

$\mathrm{b}=$ average width of beam, $\mathrm{mm}$

$\mathrm{d}=$ average depth of beam, $\mathrm{mm}$

Measured test results of ARS specimens were used to evaluate performance of basalt fibre-reinforced concrete. By comparing results obtained from specimens containing different fibre types and contents, an optimal mixture of fibre types and proportions can be established. ARS test values were normalized in the same manner as flexural test values, and the results are shown in Figures 16 and 17.

The ARS values of the tested BFRC specimens appear to be low compared to similar studies involving FRP concrete [12]. No control specimens were tested as ARS testing is intended only for comparison of different FRC mixes according to ASTM C 1399-10 [10]. Typical load-deflection curves from an ARS test is shown in Figure 18 in U.S. customary units.

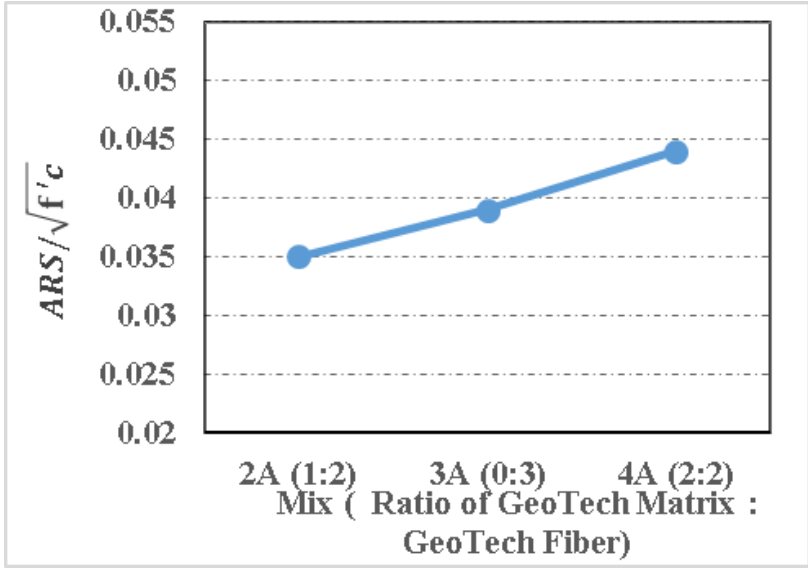

Fig.16. Normalized ARS test results, mix A.

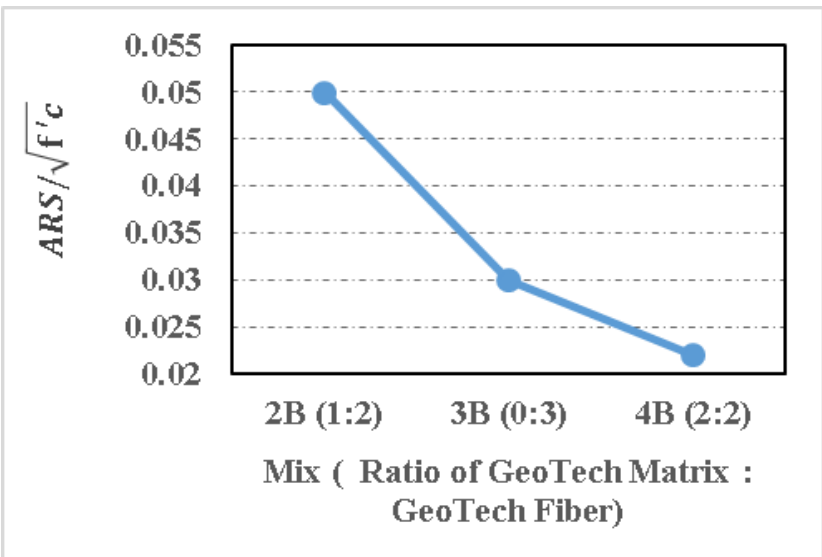

Fig.17. Normalized ARS test results, mix B.

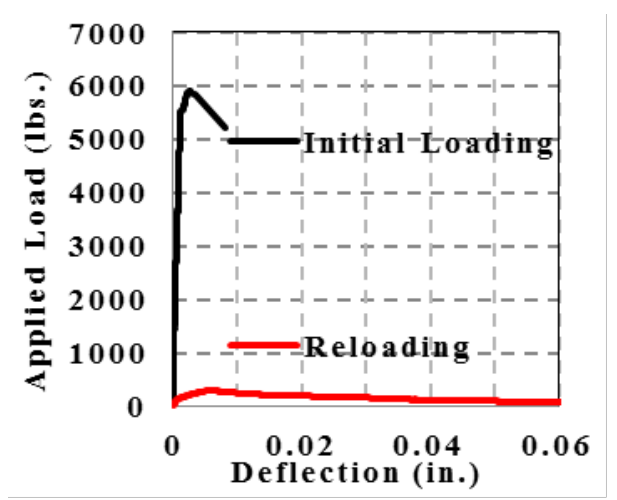

Fig. 18. Typical ARS loading and reloading curves.

As expected, the 'Initial Loading' curve is much steeper than the 'Reloading' curve, because the concrete specimen is initially un-cracked and supported by a 12 $\mathrm{mm}$ steel plate.

\section{Conclusions}

- Results indicated that the use of basalt fibre additives has insignificant effects on the compressive strength 
of plain concrete at 3,7 and 28 days, where the increase in strength did not exceed $6 \%$ in the best case. On the other hand, the use of basalt increased the compressive strength of concrete containing fly ash by a percentage ranged from $15 \%$ to $40 \%$ depending on fibre type and volume fraction.

- The research clearly indicated that basalt products increased the rupture strength of the two mixes, ' $A$ ' and ' $\mathrm{B}$ ' with percentages reached $17 \%$ and $33 \%$ respectively.

- The values of average residual strength ranged from $0.12 \mathrm{MPa}$ to $0.25 \mathrm{MPa}$, lower than similar studies involving FRP concrete.

- The ratios of GeoTech Matrix to GeoTech Fibre had no clear correlation with both the rupture strength and the average residual strength.

\section{Recommendations}

Testing compressive, flexural and average residual strength values of concrete with increased concentrations of different types of basalt fibres is recommended, in order to determine an optimal mix ratio of the two investigated basalt products. Apparently, fibre volume fractions used in this research, might be too small to have more significant effects on the investigated properties than that obtained in this study.

\section{References}

1. 'https://wiki2.org/en/Basalt_fiber', Accessed June 23 (2017)

2. T. Deak and C. Tibor, 'Chemical Composition and Mechanical Properties of Basalt and Glass Fibres : A Comparison', Textile Research Journal, 79, 7 (2009).

3. T. M. Borhan, International Journal of Civil, Environmental, Structural, Construction and Architectural Engineering, 7, 4 (2013).

4. Y. X. Yang and J. Lian, 'Basalt Fibre Reinforced Concrete, Journal of Advanced Materials Research, 194-196 (2011)

5. J. Ma, et. al., 'Experimental Research on the Fundamental Mechanical Properties of Presoaked Basalt Fiber Concrete', Proceedings of the $5^{\text {th }}$ International Conference on FRP Composites in Civil Engineering, Beijing, China, Sep. 27-29 (2010).

6. ASTM International, 'ASTM C127 : Standard Test Method for Relative Density (Specific Gravity) and Absorption of Coarse Aggregate', (2012).

7. ASTM International, 'ASTM C128: Standard Test Method for Relative Density (Specific Gravity) and Absorption of Fine Aggregate', (2012).

8. ASTM International, 'ASTM C39: Standard Test Method for Compressive Strength of Cylindrical Concrete Specimens', (2012).

9. ASTM International, 'ASTM C78: Standard Test Method for Flexural Strength of Concrete (Using Simple Beam with Third-Point Loading)', (2010).
10. ASTM International, 'ASTM C1399 : Standard Test Method for Obtaining Average Residual Strength of Fiber-Reinforced Concrete', (2010).

11. American Concrete Institute, 'ACI 318: Building Code Requirements for Structural Concrete and Commentary', (2011).

12. C. M. High, 'Use of Basalt Fibers for Reinforced Concrete Members and Concrete Materials', M.Sc. Thesis, North Carolina State University, N.C., USA, (2013). 